\title{
Effects of electrochemotherapy with cisplatin and peritumoral IL-12 gene electrotransfer on canine mast cell tumors: a histopathologic and immunohistochemical study
}

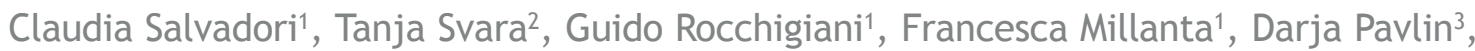 \\ Maja Cemazar ${ }^{4}$, Ursa Lampreht Tratar ${ }^{4}$, Gregor Sersa ${ }^{4}$, Natasa Tozon ${ }^{3}$, Alessandro Poli ${ }^{1}$ \\ ${ }^{1}$ Department of Veterinary Sciences, University of Pisa, Italy \\ 2 Institute of Pathology, Forensic and Administrative Veterinary Medicine, Veterinary Faculty, University of Ljubljana, \\ Ljubljana, Slovenia \\ ${ }^{3}$ Veterinary Faculty, Clinic for Companion Animals, University of Ljubljana, Ljubljana, Slovenia \\ ${ }^{4}$ Institute of Oncology Ljubljana, Ljubljana, Slovenia
}

Radiol Oncol 2017; 51(3): 286-294

Received 12 July 2017

Accepted 10 August 2017

Correspondence to: Prof. Alessandro Poli, Dipartimento di Scienze Veterinarie, Università di Pisa, Viale delle Piagge 2, 56124 Pisa, Italia. Phone: +3950 2216982; Fax: +3950 2216941, E mail: alessandro.poli@unipi.it

Disclosure. The authors declare no potential conflicts of interest.

Background. The study was aimed to characterize tumor response after combined treatment employing electrochemotherapy with IL-12 gene electrotransfer in dogs with spontaneous mast cell tumors (MCT).

Materials and methods. Eleven dogs with eleven MCTs were included in the study. Histological changes were investigated in biopsy specimens collected before the treatment $\left(T_{0}\right)$, and $4\left(T_{1}\right)$ and 8 weeks $\left(T_{2}\right)$ later. Cellular infiltrates were characterized immunohistochemically by using anti CD3, CD20, Foxp3 (Treg), CD68 and anti MHC-class II antibodies. Proliferation and anti-apoptotic activity of neoplastic cells were assessed using anti Ki-67 and BCl-2 antibodies. Angiogenetic processes were investigated immunohistochemically by using anti Factor VIII and anti CD31 antibodies and micro vessel density quantification.

Results. Histopathological examination of samples at $\mathrm{T}_{0}$ confirmed the diagnosis and the presence of scanty infiltrates consisted mainly of T-lymphocytes and macrophages. At $T_{1}$ and $T_{2}$ neoplastic cells were drastically reduced in $7 / 11$ cases, small clusters of neoplastic cells were detected in $3 / 11$ cases and $1 / 11$ cases neoplastic cells were still evident. Proliferation activity of neoplastic cells was significantly reduced at $\mathrm{T}_{1}$ and $\mathrm{T}_{2}$ and expression of anti-apoptotic protein at $\mathrm{T}_{1}$. Microvessel density was drastically reduced in all samples after treatment. The number of T-lymphocytes increased at $T_{1}$, although not significant, while Treg were significant higher at $T_{1}$ and macrophages at $T_{2}$.

Conclusions. The combined electrochemotherapy and IL-12 gene electrotransfer effectively induced a cellular response against neoplastic cells characterized mainly by the recruitment of T-lymphocytes and macrophages and a fibrotic proliferation with reduction of microvessels.

Key words: electrochemotherapy; histopathology; immune cells; interleukin-12; mast cell tumor; microvessel density

\section{Introduction}

Electrochemotherapy is an ablative technique for the treatment of solid tumors of different histotypes in human and veterinary oncology, with approximately $80 \%$ objective response of the treated tumors. ${ }^{1,2}$ It is based on electroporation as drug delivery method to tumors for the chemotherapeutic drugs bleomycin or cisplatin to improve the antitumoral efficacy. ${ }^{1}$

Another biomedical application of electroporation is plasmid DNA delivery to tumors (gene elec- 
trotransfer) for gene therapy. Preclinical and clinical studies demonstrated effectiveness of different therapeutic plasmid DNA electrotransfer to tumors as effective and safe method for local as well as loco-regional control of the cutaneous tumors. ${ }^{3}$ The most studies explored gene electrotransfer of plasmid DNA coding for IL-12 cytokine. ${ }^{4-6}$ Its effectiveness was demonstrated also in treatment of spontaneous tumors in dogs. ${ }^{7-10}$

A new treatment approach is combining local tumor electrochemotherapy with gene therapy with plasmid coding for IL-12 peritumorally to skin. ${ }^{11}$ Some preclinical data indicate that this approach provides in situ vaccination by electrochemotherapy that is boosted by immunogene IL-12 peritumoral gene electrotransfer. ${ }^{3}$

Our previous report has provided evidence for this approach in MCT with excellent local tumor control and long lasting progression free survival of the treated dogs. ${ }^{11}$ To provide further evidence on the mechanisms of action, this study evaluates the histopatological features of those tumors in more detail to characterize whether this approach provides antitumor response also due to boosting the immune response. Therefore, we characterized tumor response including the cellular infiltrates at different time points post-electrochemotherapy with cisplatin combined with peritumoral IL-12 electrotransfer in dogs, spontaneously affected by MCT and compared these results with those observed in biopsies collected before the treatment. Proliferation and anti-apoptotic activity of neoplastic cells as well as the changes in microvessel density were also investigated, at the same timing.

\section{Materials and methods}

\section{Animals and tumors}

Between January and December 2010 eleven subjects, 4 males and 7 females of different breeds ranging from 5 to 9 year-old (mean 6.5 years \pm 1.3 years) complied with inclusion criteria for the clinical survey (histologically confirmed MCT in different anatomical locations, good general health conditions with normal routine hematologic and biochemical profile without cardiac dysfunctions), were included in the study. The animals included in the study were those that owners refused any other type of standard treatment/surgery with wide excision of nodules.

Before the treatment a staging in all patients was performed according to modified WHO staging criteria with physical examination, examination of tho- racic radiographs, abdominal ultrasonography and basic bloodwork, consisting of a complete blood count with differential white cell count. Biochemical parameters (urea, creatinine, serum alkaline phosphatase and alanine aminotransferase) were determined using an automated chemical analyzer.

The study was approved by the Ethical Committee of the Ministry of Agriculture, Forestry and Food of the Republic of Slovenia (approval No. 323-451/2004-9). Prior to the inclusion a written consent for participation in the clinical study for each animal was obtained from their owners.

\section{Electrochemotherapy and gene transfer}

Electrochemotherapy and IL-12 gene electrotransfer were performed as previously described. ${ }^{11}$ Briefly, electrochemotherapy with intratumoral injection of cisplatin (cis-diamminedichloroplatinum II, Cisplatyl; Aventis, Paris, France), at a concentration of $2 \mathrm{mg} / \mathrm{ml}$ in a dose of $\sim 1 \mathrm{mg} / \mathrm{cm}^{3}$ was performed just before electric pulses were delivered (8 pulses each of $100 \mu$ s duration and amplitude to electrode distance ratio of $1300 \mathrm{~V} / \mathrm{cm}$ and frequency of repetition $5 \mathrm{kHz}$ with electric pulses generator Cliniporator $^{\mathrm{TM}}$ (IGEA s.r.l., Carpi, Italy)). Two parallel stainless steel plate electrodes with 6 $\mathrm{mm}$ distance between them or 4 needle row electrodes with $4 \mathrm{~mm}$ distance according to the tumor size was used. Immediately after the electrochemotherapy $2 \mathrm{mg}$ of the IL-12 plasmid was injected intradermally in equidistant locations around tumor nodule in two locations. ${ }^{10}$ One high voltage pulse (amplitude to electrode distance ratio $1200 \mathrm{~V} / \mathrm{cm}$, duration $100 \mu \mathrm{s}$ ) and one low voltage pulse (amplitude to electrode distance ratio $140 \mathrm{~V} / \mathrm{cm}$, duration $400 \mu \mathrm{s})^{12}$ were delivered immediately after plasmid injection, using the same electric pulse generator and electrodes as mentioned above.

\section{Tissue sampling and processing}

All the subjects were submitted to biopsy before $\left(\mathrm{T}_{0}\right)$ the combined therapy and at $4\left(\mathrm{~T}_{1}\right)$ and 8 weeks $\left(\mathrm{T}_{2}\right)$ post-treatment. Biopsies were fixed into $10 \%$ neutral buffered formalin and then processed routinely for paraffin embedding. Five-micrometers serial sections from all specimens were stained for haematoxylin and eosin (HE), Gomori's modified trichrome stain and also mounted on treated glass slides (Superfrost Plus; Menzel-Glaser, Germany) for immunohistochemistry. Mast cell tumors were classified according to the Kiupel et al. (2011) classification. ${ }^{13}$ 
TABLE 1. Antibodies used in the study

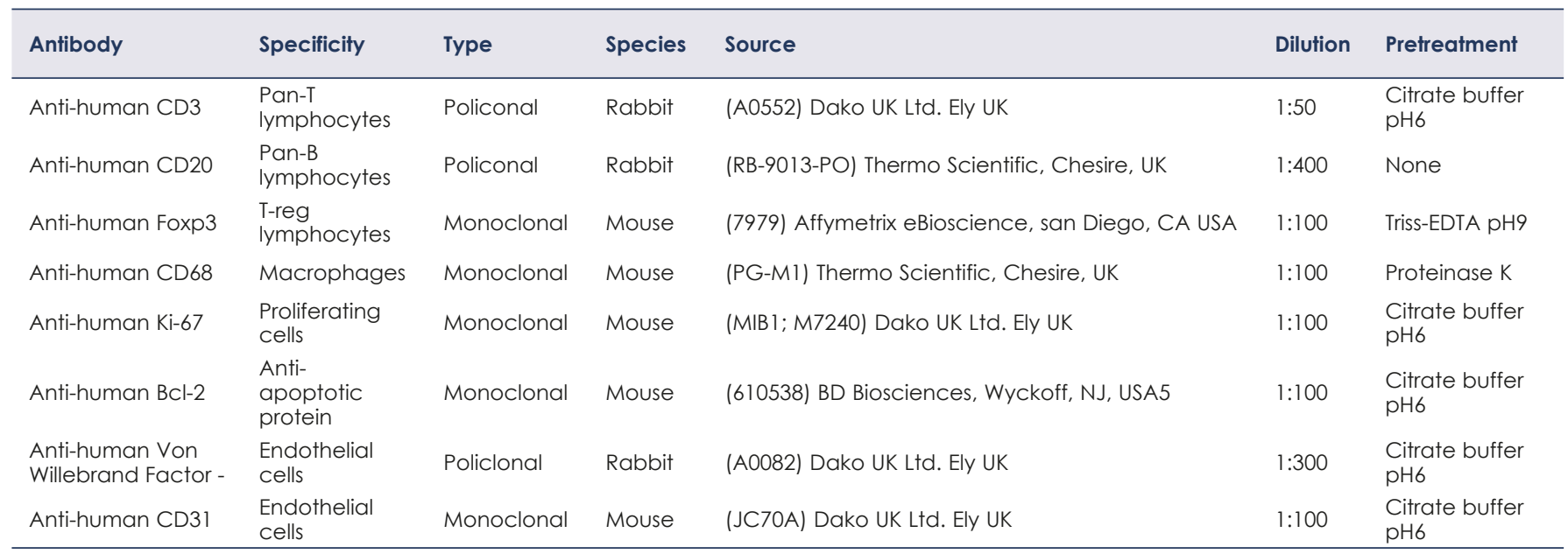

\section{Immunohistochemistry}

Sections were dewaxed in xylene and rehydrated through graded alcohols prior to quenching endogenous peroxidase activity with $3 \% \mathrm{H}_{2} \mathrm{O}_{2}$ in distilled water for 20 minutes. Heat induced epitope retrieval with citrate buffer $\mathrm{pH} 6$ was performed. Immunohistochemical labelling was performed manually with the Sequenza slide rack and cover-plate system (Shandon, Runcorn, UK). Non-specific antigen binding was blocked by incubation with UltraVision Protein Block (TA-125PBQ; Thermo Scientific, Cheshire, UK). A panel of primary antibodies was applied to serial sections and incubated overnight at $4^{\circ} \mathrm{C}$ (Table 1). Antibody binding was detected by the Biotinylated Goat Polyvalent Secondary (TP-125-BN; Thermo Scientific, Cheshire, UK), Streptavidin Peroxidase (TS-125-HR; Thermo Scientific, Cheshire, UK) and DAB chromogen (SK-4105; ImmPact DAB, Vector, Burlingame, CA) as indicated by manufacturer's instructions and slides were counterstained with haematoxylin. Substitution of the primary antibody with unrelated matched primary antibody was used to provide a negative control. Serial sections of canine lymph node were used as positive control.

Slides were examined by two pathologists (C.S. and A.P.) without knowledge of the corresponding clinical and pathological data.

\section{Quantification of immunolabeling}

Bright field images were acquired at X20 magnification with a Leica Microsystem DFC490 digital camera mounted on Leica DMR microscope (Wetzlar,
Germany). Counting were performed using a semiautomatic analysis system (LASV 4.3, Leica). Six $10,000 \mu \mathrm{m}^{2}$ random fields of the central and periphery parts of the biopsies were used for counting the number of infiltrating CD3+, CD20+, Foxp3+ (Treg+), CD68+ and MHC Class II+ cells and Bcl$2+$ and Ki-67+ neoplastic cells. Microvessel density was determined with Factor VIII and CD31 immunostained section in six 50,000 $\mu^{2}$ random fields.

\section{Statistical analysis}

Statistical analysis was performed using the statistical package SPSS Advanced Statistics 21.0 (SPSS Inc., Chicago, IL, USA). ANOVA test was used to compare the composition of cell infiltrates and microvessel density at the different times of observation and post hoc analysis was made by Bonferroni Test. Statistical significance was based on a $5 \%$ (0.05) significance level.

\section{Results}

\section{Histologic features}

At $\mathrm{T}_{0}$, all eleven skin tumors of different volumes (ranged from 0.2 to $16.9 \mathrm{~cm}^{3}$ ) were diagnosed as low grade MCTs and were characterized by sheets of polygonal neoplastic cells with abundant cytoplasm containing variable number of metachromatic granules, associated with moderate to massive infiltration of eosinophils, in the superficial and deep dermis, sometimes extending also to deep muscular layer (Figure 1A). Mitotic index was low (1 to 2 mitoses/10 HPF). Scanty multinucleated cells were observed. Rarely necrotic areas 
were present. Neoplastic cells were associated with reactive proliferation of connective tissue.

At $\mathrm{T}_{1}$ in biopsies collected from seven dogs with complete response, the neoplastic tissue was substituted by a fibrotic tissue composed by horizontally oriented wavy collagen fibers associated with inflammatory infiltrates mainly constituted by lymphocytes and macrophages (Figure 1B). In three cases (partial response), single or small clusters of neoplastic cells were still evident scattered among the fibrotic connective tissue, while in one dog neoplastic mast cells were still evident with features similar to $\mathrm{T}_{0}$.

At $T_{2}$ biopsies collected from the seven dogs which did not present tumor cells at $T_{1}$ were still free of neoplastic cells and consisted of a dense fibrous tissue still infiltrated by mononuclear cells. In other three cases (one with stable disease and two with partial response), thin aggregates of neoplastic mast cells between connective tissue bundles, were still evident (Figure 1C), while in one case with partial response, neoplastic cells were numerous as at $\mathrm{T}_{0}$ and $\mathrm{T}_{1}$.

\section{Immunohistochemistry}

Immunohistochemical analysis of biopsies collected before the treatment and at different times of post-treatment revealed, in dermal infiltrates the presence of $\mathrm{CD} 3+\mathrm{T}$ lymphocytes (Figure 2A, B), CD20+ B lymphocytes, Treg Lymphocytes (Figure 2C, D), and macrophages (Figure 2E, F), in different percentages, with $\mathrm{T}$ lymphocytes and macrophages representing the predominant cell populations. Results of immunohistochemical evaluation of inflammatory infiltrates at $\mathrm{T}_{0}$ and at $\mathrm{T}_{1}$ and $\mathrm{T}_{2}$ intervals are presented in the Figure 3. Overall, the $\mathrm{T}$ lymphocyte number increased at $\mathrm{T}_{1}$, even this difference was not statistically significant and was reduced at $T_{2}$. Specifically, in biopsies collected from subjects with complete remission, the number of $\mathrm{CD} 3+$ lymphocytes was significantly higher than from dogs with stable or progressive disease both at both $\mathrm{T}_{1}(8.1 \pm 8.2 \mathrm{CD} 3+$ cells/ 10,000 $\mathrm{mm}^{2}$ vs $3.4 \pm 1.9$ CD3+cells/ 10,000 $\mathrm{mm}^{2} ; \mathrm{p}=0.008$ ) both at $\mathrm{T}_{2}\left(6.6 \pm 4.4 \mathrm{CD} 3+\right.$ cells/ $10,000 \mathrm{~mm}^{2}$ vs $3.2 \pm$ $1.9 \mathrm{CD} 3+$ cells $\left./ 10,000 \mathrm{~mm}^{2} ; \mathrm{p}=0.001\right)$. Macrophages significantly increased at $\mathrm{T}_{2}(\mathrm{P}=0.006)$ and Treg lymphocytes significantly increased at $T_{1}(p=$ 0.0001 ), but no differences were observed at $T_{2}$. No differences were observed in the presence of CD20 lymphocytes at $\mathrm{T}_{1}$ and $\mathrm{T}_{2}$.

Immunohistochemical studies allowed to determine also the presence of proliferative and anti-ap-
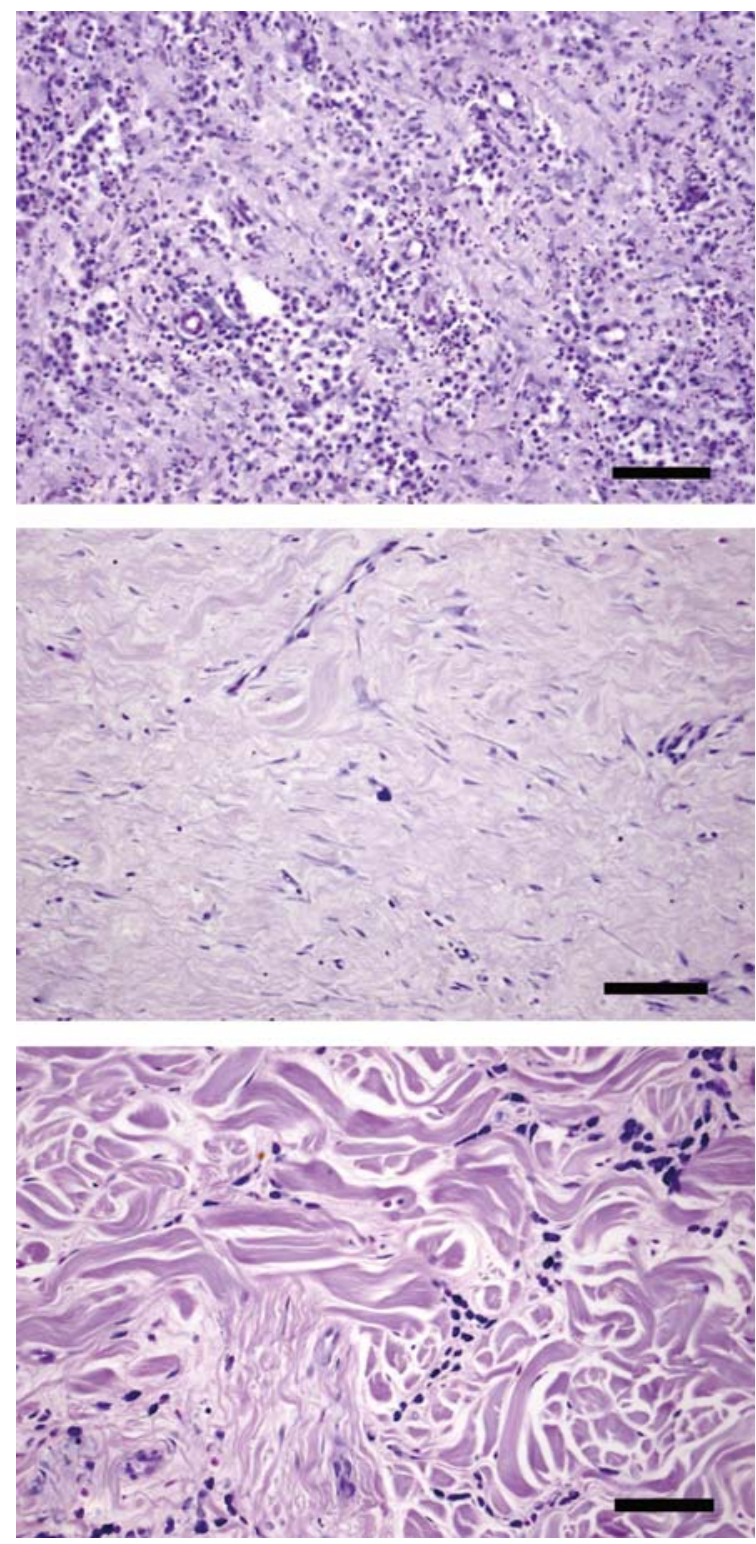

FIGURE 1. Histology of tissue samples collected before the combined therapy $\left(T_{0}\right)$ and at $4\left(T_{1}\right)$ and 8 weeks $\left(T_{2}\right)$ post-treatment. (A) At $T_{0}$ sheets of neoplastic cells with abundant cytoplasm containing variable number of metachromatic granules were present in the superficial and deep dermis; (B) At T, The neoplastic tissue was substituted by a fibrotic tissue associated with scanty inflammatory infiltrates mainly constituted by mononuclear cells; (C) At $\mathrm{T}_{2}$ in dogs with partial response between connective tissue bundles were evident thin aggregates of neoplastic mast cells. Haematoxylin Eosin; bar $=100 \mathrm{~mm}$.

optotic activities of neoplastic cells (Figure 4A, B; and $\mathrm{C}, \mathrm{D}$, respectively) as well as the micro-vessel density (Figure $4 \mathrm{E}, \mathrm{F}$ ) at $\mathrm{T}_{0}, \mathrm{~T}_{1}$ and $\mathrm{T}_{2}$. Results were summarized in the Figure 5.

Proliferation activity of neoplastic cells was statistically reduced at $\mathrm{T}_{1}(\mathrm{p}=0.0001)$ and $\mathrm{T}_{2}(\mathrm{p}=$ 0.0001 ), while the number of neoplastic cells ex- 


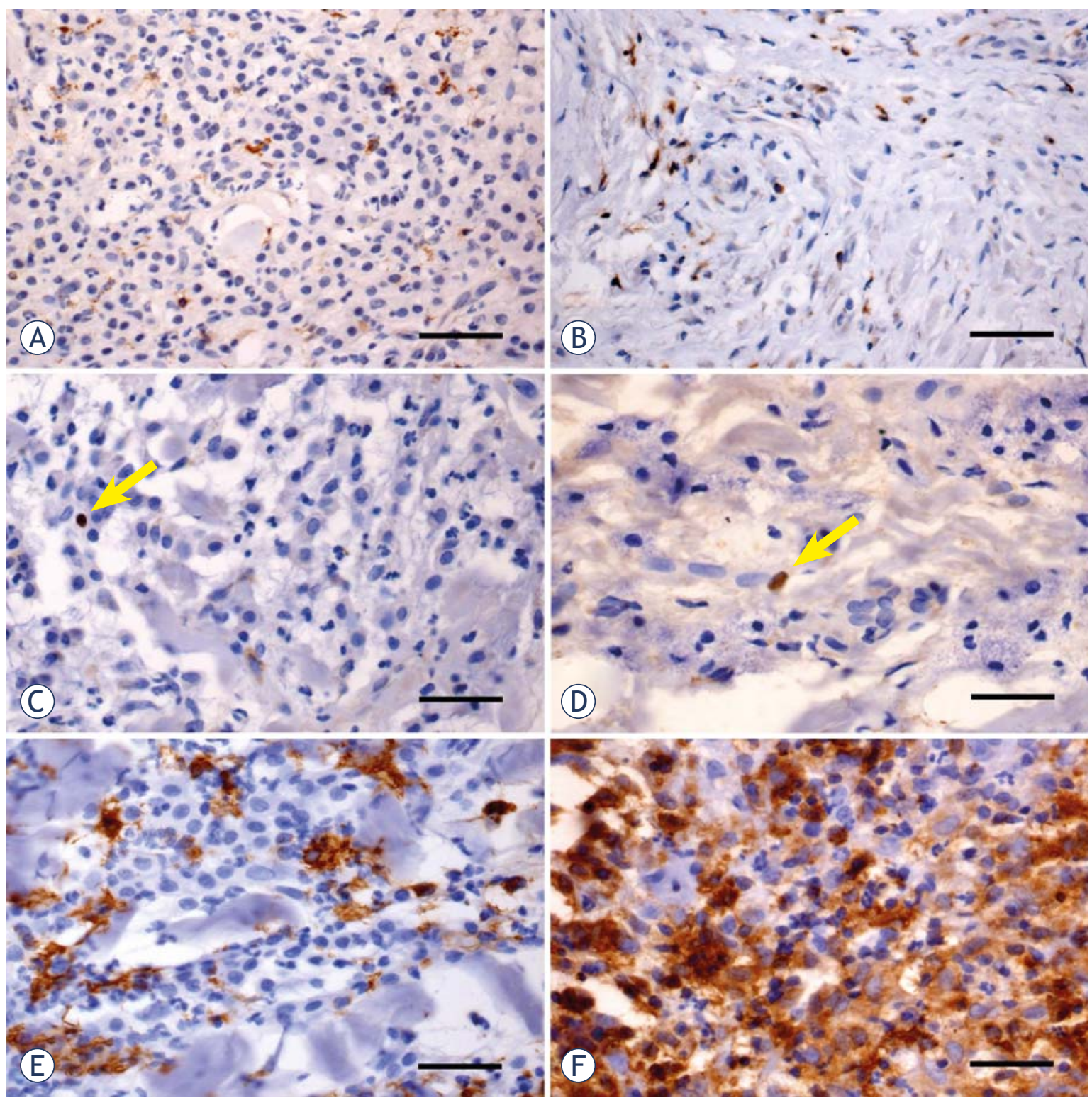

FIGURE 2. Immunoistochemical staining of tissue samples collected at $T_{0}(A, C$ and $E)$ and, $T_{1}$ (B, D and E). CD3+ lymphocytes infiltrating the neoplastic tissue at $T_{0}(A)$ and the fibrotic tissue at $T_{1}(B)$. Scanty Foxp3+ Treg lymphocytes at the periphery of neoplastic tissue at $\mathrm{T}_{0}(\mathrm{C})$ and in a tissue sample collected at $\mathrm{T}_{1}(\mathrm{D})$. CD68+ macrophages in the neoplastic tissue at $\mathrm{T}_{0}(\mathrm{E})$ and in the fibrotic tissue at $T_{1}(F)$. Immunohistochemical staining using DAB chromogen and haematoxylin counterstain. Bar $=100 \mathrm{~mm}$.

pressing the Bcl-2 anti-apoptotic protein was increased at $\mathrm{T}_{1}(\mathrm{p}=0.0001)$, while was reduced 4 weeks later. Proliferation activity of neoplastic cells in the biopsies collected from subjects with complete response was significantly lower than in the biopsies collected from dogs with stable or progressive disease both at $\mathrm{T}_{1}(1.5 \pm 2.1 \mathrm{Ki}-67+$ cells/ $10,000 \mathrm{~mm}^{2}$ vs $2.5 \pm 0.7 \mathrm{Ki}-67+$ cells $/ 10,000 \mathrm{~mm}^{2} ; \mathrm{p}=$ $0.012)$ both at $\mathrm{T}_{2}\left(0.4 \pm 0.6 \mathrm{Ki}-67+\right.$ cells $/ 10,000 \mathrm{~mm}^{2}$ vs $2.2 \pm 1.0 \mathrm{Ki}-67+$ cells/ 10,000 $\mathrm{mm}^{2} ; \mathrm{p}=0.0001$ ), as well as the expression of anti-apoptotic Bcl-2 protein both at both $\mathrm{T}_{1}(1.9 \pm 2.0 \mathrm{Bcl}-2+$ cells/ 10,000 $\mathrm{mm}^{2}$ vs $3.2 \pm 0.9 \mathrm{Bcl}-2+$ cells/ 10,000 $\mathrm{mm}^{2} ; \mathrm{p}=0.004$ ) both at $\mathrm{T}_{2}\left(1.4 \pm 1.5 \mathrm{Ki}-67+\right.$ cells/ $10,000 \mathrm{~mm}^{2}$ vs $2.8 \pm$ $1.2 \mathrm{Ki}-67+$ cells/ 10,000 mm²; p = 0.0001).

Microvessel density, determined using both anti-Factor VIII and anti-CD31 antibodies, was drastically reduced at $T_{1}(p=0.000)$ and $T_{2}(p=0.0001)$, when compared with the samples collected before the treatment. 


\section{Discussion}

Histopathological evaluation of tissue biopsies after electrochemotherapy with cisplatin combined with peritumoral IL-12 gene electrotransfer demonstrates that in the tumors with complete clinical response, pronouncedly reduced number and proliferation rate of the tumor cells was obtained with significantly enhanced immune and anti-vascular response, which confirm our previously reported clinical results. ${ }^{11}$

At the best of our knowledge this is the first clinical study that describes the histopathological and cellular changes induced in vivo by electrochemotherapy and peritumoral IL-12 electrotransfer in dogs bearing MCT, performed with the consent of the owners. The number of biopsies was reduced and made at distance from treatment with the aim to verify its effectiveness.

Already at four weeks post-treatment, in dogs with a complete responses histopathologic examination revealed a marked reduction of neoplastic cells, confirming the anticancer efficacy of the combined electrochemotherapy and gene therapy. This reduction was even more evident four weeks later. On the contrary, in dogs with a partial response the reduction of neoplastic cell was lower at four weeks after treatment and this reduction was absent in dog with stable disease.

The reduced presence of neoplastic cells detected in the tissue samples from dogs with complete response was also associated with a reduced proliferative activity of remnant neoplastic mast cells, characterized by a significant reduction of positivity to Ki-67 antibody and by a significant reduced expression of the anti-apoptotic Bcl-2 protein. The major mechanism of cisplatin tumor destruction consists of the formation of intrastrand and interstrand DNA adducts leading to DNA fragmentation that can ultimately lead to an apoptotic mediate cell death as demonstrated in vitro and in vivo in murine models ${ }^{14}$ and the decreased expression of anti-apoptotic factor as the Bcl-2 protein promotes higher death rate of the cancer cells. ${ }^{15}$

The time interval of 4 weeks of the first posttreatment biopsy did not allow evaluation of the tumor necrosis, since at this time point dense fibrotic connective tissue with progressive reduction of microvessel density was already present. In experimental animal models has been demonstrated that electroporation induces a higher internalization of cisplatin molecules with a rapid necrosis of neoplastic cells ${ }^{16}$ and vascular disrupting action by causing a rapid shutdown of tumour blood flow

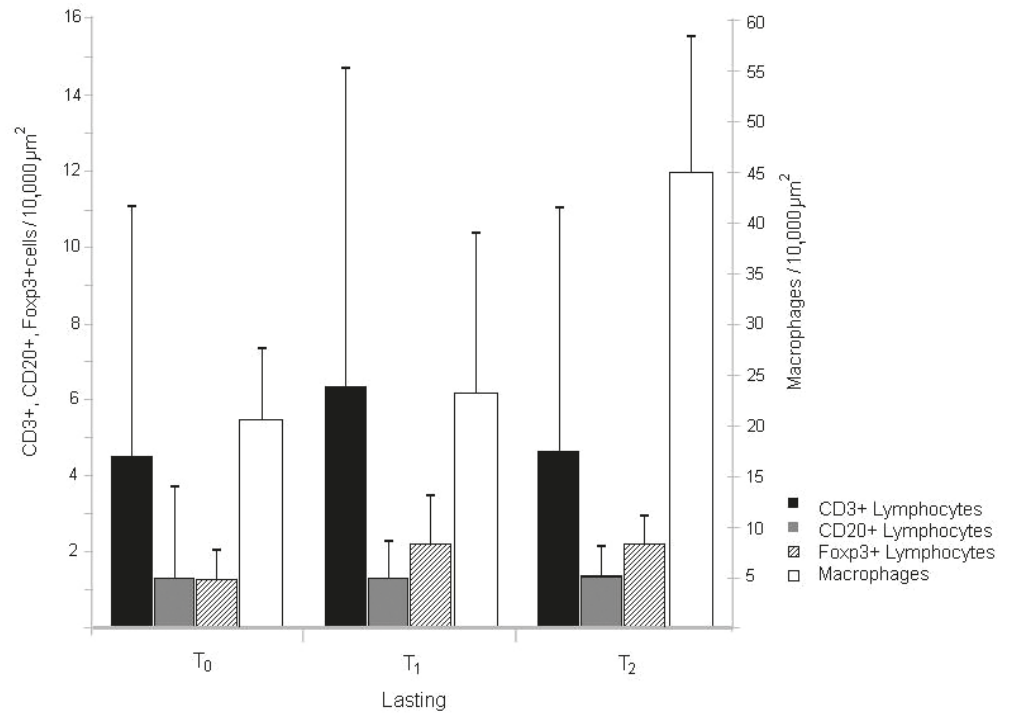

FIGURE 3. Histogram of number of immune cells in $10,000 \mu \mathrm{m}^{2}$ of tissue samples collected al $T_{0}, T_{1}$ and $T_{2}$. Slight increase of CD3+ lymphocytes at $T_{1}$, while macrophages significantly increased at $T_{2}$ and Treg lymphocytes at $T_{1}$.

leading to reduced tumour oxygenation, increased tumour hypoxia and tumour necrosis. ${ }^{17}$

In this study, electrochemotherapy was associated with IL-12 gene electrotransfer with proven good local and locoregional antitumor effects. ${ }^{11}$ The potential for inducing an antitumoral immune response to treat neoplastic disorders is well known, but the application of this technology has not yet been meaningfully transferred to the clinic. Local administration of recombinant cytokines directly into the tumor has proven to be much safer than systemic delivery. ${ }^{13}$ IL-12 is a natural occurring cytokine that showed potential success for treating cancer by inducing a specific anti-tumoral immune response. ${ }^{18}$ Gene therapy with IL-12 pDNA showed to be effective to treat multiple tumor histotype in rodent models and induce an anti-tumoral immune response capable of affecting neoplastic tissues. ${ }^{14-16}$ Likewise, IL-12 gene therapy in canine species can induce tumor regression in spontaneous neoplasms of different histotypes. ${ }^{17,19,20}$

Another therapeutic approach that is currently extensively explored is combination of the ablative techniques with different immunomodulatory approaches, either with immune checkpoint inhibitors, Treg depletion or immunostimulation. ${ }^{3}$ In this context ablative techniques are considered as in situ vaccination with further boosting of the immune responsiveness of the organism. For this purpose, we postulated that electrochemotherapy 


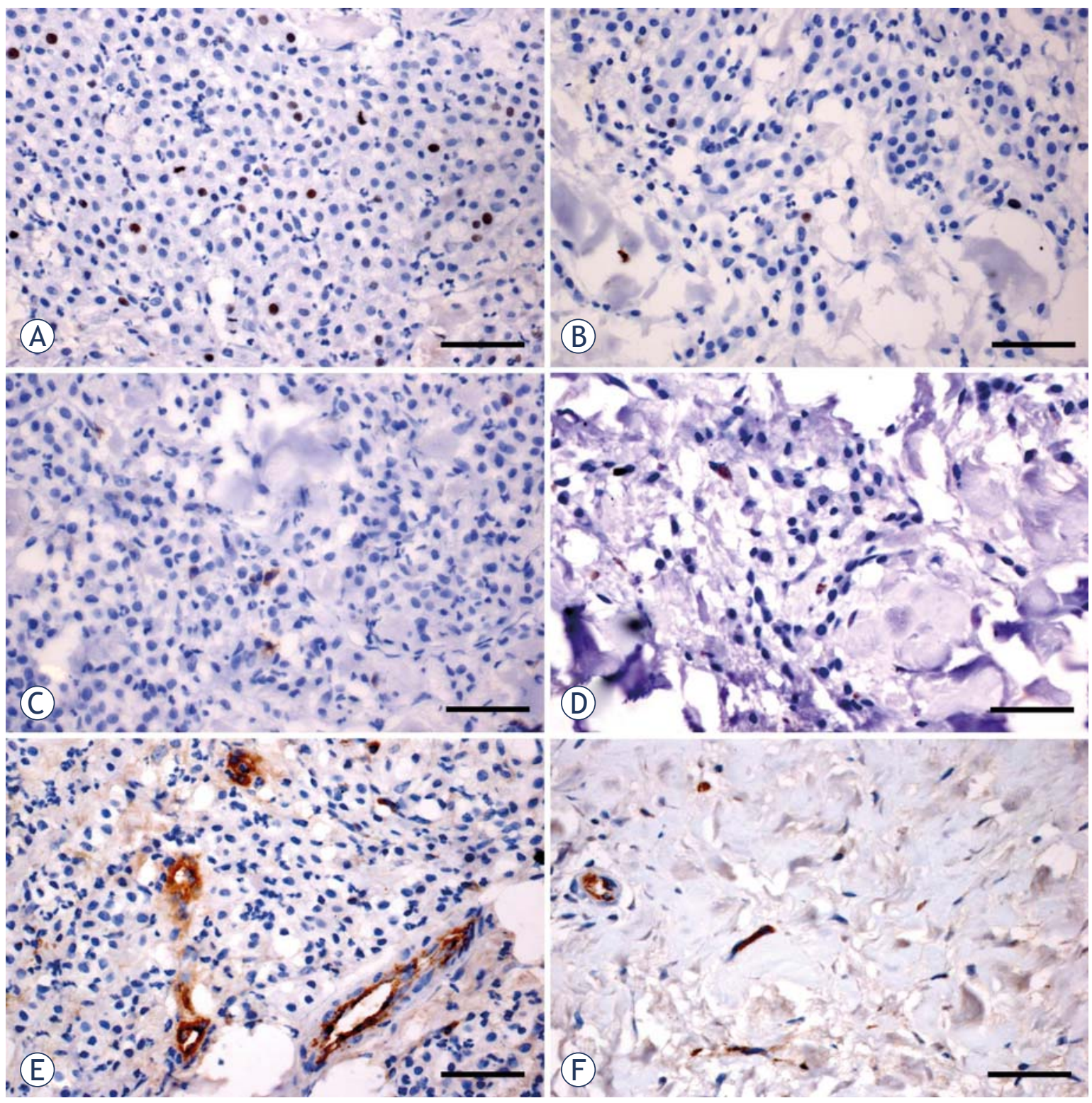

FIGURE 4. Immunoistochemical staining of tissue samples collected at $T_{0}(A, C$ and $E)$ and, $T_{1}(B, D$ and E). Ki-67+ neoplastic cells at $T_{0}$ (A) and at $T_{1}$ in a dog with partial response (B). BCl-2+ neoplastic cells at $T_{0}$ (C) and at $T_{1}$ in a dog with partial response (D). Microvessels stained using an anti-CD31 primary antibody at $\mathrm{T}_{0}(\mathrm{E})$ and in the fibrotic tissue at $\mathrm{T}_{1}$ in a dog with a complete response (F). Immunohistochemical staining using DAB chromogen and haematoxylin counterstain. Bar $=100 \mathrm{~mm}$.

could be in situ vaccination, which can be boosted with peritumoral IL-12 gene electrotransfer, given peritumorally. ${ }^{3}$ Our clinical study on MCT supports this hypothesis, providing evidence that this treatment combination has excellent local tumor control and also the long lasting disease free interval (between 3 and 4 years). Furthermore the present study immunohistologically supports the value of peritumoral IL-12 gene electrotransfer in boosting immune response of the organism, providing evidence of the presence of immune cells
(T-lymphocytes and macrophages) in the tumors treated with electrochemotherapy and peritumoral IL-12 gene electrotransfer compared to tumors before therapy. There is also another study on sarcoids in horses, using the same combined treatment in which increased number of CD4 and CD8 lymphocytes sub-population confirmed induction of local immune response in treated tumors. ${ }^{21}$

Even though in our study the number of examined biopsies was limited, at 4 weeks post-treatment our immunohistochemical results unequivo- 
cally demonstrated an increase of T-lymphocytes in cellular infiltrates, higher in subjects with a complete response. T cells are the essential components of the adaptive immune response and they interact closely with antigen presenting cells to release various cytokines that characterize the specific immune response also to neoplastic cells. The T-lymphocyte increase detected after four weeks post treatment was not evident 4 weeks later, indicating that probably the anti-tumoral immune response induced by IL-12 is only transient as previously hypothesized or that due to the complete tumor regression, they could not be observed in higher numbers in the biopsies. ${ }^{15}$

The presence of B cells in examined subjects was not affected by IL-12 gene electrotransfer 4 as well as 8 weeks after the treatment. On the contrary, macrophages increased 8 weeks post-treatment, which was not related with the response to the therapy. The macrophages, as any innate immune cells, act when tissue homeostasis is perturbed, releasing soluble mediators such as cytokines, chemokines, matrix remodeling proteases and reactive oxygen species and contribute to the maintenance of the inflammation and this late increase of these cells detected in treated subjects should be related with the tissue damage induced by the therapy.

Tregs play an important role in down regulating immune responses and an imbalance between numbers of Tregs and CD4+ and CD8+ T-lymphocytes contributes to the outcomes in cancer and infectious diseases. Many studies have demonstrated the in vivo role of these cells in the suppression of the immune response to the cancer in human ${ }^{22,23}$ and veterinary oncology..$^{24,25}$ While Treg are immunosuppressive at sites of inflammation, the increase detected in our study should be explained by previous studies demonstrating that the adjuvant activity of IL-12 is short-lived due to regulatory Treg re-infintration. In fact, quantitative analysis of Treg kinetics in IL-12 treated tumors revealed a transient loss of these cells followed by a rapid fold expansion of tumor Treg between days 3 and 10 post treatment. ${ }^{26}$ So the increase of Treg observed in our study should be related with the timing of tissue sampling after the treatment or due to the presence of inflammation.

In conclusion, our study confirmed the synergic power of electrochemotherapy and IL-12 gene electrotransfer in canine species at immunohistopathological level. It led to number of complete responses and extends survival through the induction of interferon gamma, inhibiting angiogenesis and increasing cytotoxic activity. ${ }^{3}$

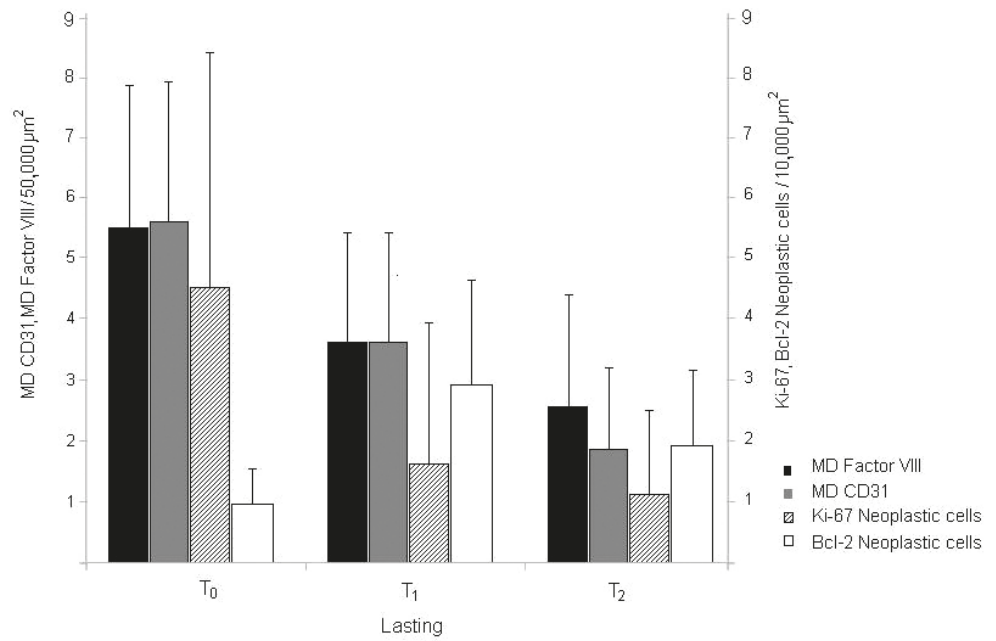

FIGURE 5. Histogram of microvessel density determineg using both primary antibodies against Factor VIII and CD31 positive-cells in 50,000 $\mathrm{mm}^{2}$ of tissue samples and number of $\mathrm{Ki}-67+$ and $\mathrm{BCl}-2+$ neoplastic cells in $10,000 \mathrm{\mu m}^{2}$ of tissue samples collected al $\mathrm{T}_{0}$, $T_{1}$ and $T_{2}$. Microvessel density was drastically reduced at $T_{1}$ and $T_{2}$. as well as the proliferation activity of neoplastic cells, while Bcl-2 expression was increased at $\mathrm{T}_{1}$.

\section{Acknowledgements}

Slovenian Research Agency has supported this research by grants P3-0003 (Gregor Sersa), P4-0053 (Milka Vrecl Fazarinc), J3-6796 (Maja Cemazar). Research was conducted in the scope of the EBAM European Associated Laboratory (LEA) and resulted from the networking efforts of the COST Action TD1104 (www.electroporation.net).

\section{References}

1 Campana L, Clover AJP, Valpione S, Quaglino P, Gehl J, Kunte C, et al. Recommendations for improving the quality of reporting clinical electrochemotherapy studies based on qualitative systematic review. Radiol Oncol 2016; 50: 1-12. doi:10.1515/raon-2016-0006

2 Cemazar M, Tamzali Y, Sersa G, Tozon N, Mir LM, Miklavcic D, et al. Electrochemotherapy in veterinary oncology. J Vet Int Med 2008; 22: 82631. doi:10.1111/j.1939-1676.2008.0117.x

3 Sersa G, Teissie J, Cemazar M, Signori E, Kamensek U, Marshall G, et al. Electrochemotherapy of tumors as in situ vaccination boosted by immunogene electrotransfer. Cancer Immunol Immunother 2015; 64: 1315-27. doi:10.1007/s00262-015-1724-2

4 Sedlar A, Dolinsek T, Markelc B, Prosen L, Kranjc S, Bosnjak M, et al. Potentiation of electrochemotherapy by intramuscular IL-12 gene electrotransfer in murine sarcoma and carcinoma with different immunogenicity. Radio Oncol 2012; 46: 302-11. doi:10.2478/v10019-012-0044-9

5 Kishida T, Asada H, Itokawa Y, Yasutomi K, Shin-Ya M, Gojo S, et al. Electrochemo-gene therapy of cancer: intratumoral delivery of interleukin-12 gene and bleomycin synergistically induced therapeutic immunity and suppressed subcutaneous and metastatic melanomas in mice. Mol Ther 2003; 8: 738-45.

6 Torrero MN, Henk WG, Li S. Regression of high-grade malignancy in mice by bleomycin and interleukin-12 electrochemogenetherapy. Clin Cancer Res 2006; 12: 257-63. doi:10.1158/1078-0432.CCR-05-1514 
7 Cutrera J, Torrero M, Shiomitsu K, Mauldin N, Li S. Intratumoral bleomycin and IL-12 electrochemogenetherapy for treating head and neck tumors in dogs. Methods Mol Biol 2008; 423: 319-25. doi:10.1007/978-1-59745-1949_24

8 Cutrera J, King G, Jones P, Kicenuik K, Gumpel E, Xia X, et al. Safety and efficacy of tumor-targeted interleukin 12 gene therapy in treated and nontreated, metastatic lesions. Curr Gene Ther 2015; 15: 44-54.

9 Cutrera J, King G, Jones P, Kicenuik K, Gumple E, Xia X, et al. Safe and effective treatment of spontaneous neoplasms with interleukin 12 electrochemo-gene therapy. J Cell Mel Med 2015, 19: 664-75. doi:10.1111/ jcmm.12382

10 Pavlin D, Cemazar M, Coer A, Sersa G, Pogacnik A, Tozon N. Electrogene therapy with interleukin-12 in canine mast cell tumors. Radiol Oncol 2011; 45: 31-9. doi:10.2478/v10019-010-0041-9

11 Cemazar M, Ambrozic Avgustin J, Pavlin D, Sersa G, Poli A, Krhac Levacic A, et al. Efficacy and safety of electrochemotherapy combined with peritumora IL-12 electrotransfer of canine mast cell tumors. Vet Comp Oncol 2017; 15 641-4. doi:10.1111/vco.12208

12 Pavselj N, Preat V. DNA electrotransfer into the skin using a combination of one high- and one low-voltage pulse. J Control Release 2005; 106: 407-15. doi:10.1016/j.jconrel.2005.05.003

13 Kiupel M, Webster JD, Bailey KL, Best S, DeLay J, Detrisac CJ, et al. Proposa of a 2-tier histologic grading system for canine cutaneous mast cell tumors to more accurately predict biological behavior. Vet Pathol 2011; 48: 147-55. doi:10.1177/0300985810386469

14 Jamieson ER, Lippard SJ. Structure, recognition, and processing of cisplatinDNA adducts. Chem Rev 1999; 99: 2467-98.

15 Scarfò L, Ghia P. Reprogramming cell death. BCL2 family inhibition in hematological malignancies. Immunol Lett 2013; 155: 36-9. doi:10.1016/j. imlet.2013.09.015

16 BelehradekJ, OrlowskiS, Poddevin B, PaolettiC, Mir LM. Electrochemotherapy of spontaneous mammary tumours in mice. Eur J Cancer 1991; 27: 73-6.

17 Sersa G, Jarm T, Kotnik T, Coer A, Podkrajek M, Sentjurc M. Vascular disrupting action of electroporation and electrochemotherapy with bleomycin in murine sarcoma. Br J Cancer 2008; 98: 388-98. doi:10.1038/sj.bjc.6604168

18 Trinchieri G. Interleukin-12 and the regulation of innate resistance and adaptive immunity. Nat Rev Immunol 2003; 3:133-46. doi:10.1038/nri1001

19 Cutrera J, Li S. Passive and active tumor homing cytokine therapy. In Lustgarten J, Cui Y, Li S, editors. Targeted cancer immune therapy. New York: Springer; 2009. p. 97-113.

20 Del Vecchio M, Bajetta E, Canova S, Lotze MT, Wesa A, Parmiani G, et al. Interleukin-12: biological properties and clinical application. Clin Cancer Res 2007; 13: 4677-85. doi:10.1158/1078-0432.CCR-07-0776

21 Tamzali Y, Borde L, Rols MP, Golzio M, Lyazrhi F, Teissie J. Successful treatment of equine sarcoids with cisplatin electrochemotherapy: a retrospective study of 48 cases. Equine Vet J 2012; 44: 214-20. doi:10.1111/j.20423306.2011.00425.x

22 Curiel TJ, Coukos G, Zou L, Alvarez X, Cheng P, Mottram P, et al. Specific recruitment of regulatory $T$ cells in ovarian carcinoma fosters immune provolege and predicts reduced survival. Nat Med 2004; 10: 942-9. doi:10.1038/ nm1093

23 Zhou J, Ding T, Pan W, Zhu LY, Li L, Zheng L. Increased intratumoral regulatory $T$ cells are related to intratumoral macrophages and poor prognosis in hepatocellular carcinoma patient. Int J cancer 2009, 125: 1640-8. doi:10.1002/ ijc.24556

24 Kim JH, Hur JH, Lee SM, Im KS, Kim NH, Sur JH. Correlation of Foxp3 positive regulatory $\mathrm{T}$ cells with prognostic factors in canine mammary carcinomas. Vet J 2012; 193: 222-7. doi:10.1016/j.tvjl.2011.10.022

25 Oh SY, Ryu HH, Yoo DY, Hwang IK, Kweon OK, Kim WH. Evaluation of FOXP3 expression in canine mammary gland tumours. Vet Comp Oncol 2014; 12 20-8. doi:10.1111/j.1476-5829.2012.00327.x

26 Li Q, Virtuoso LP, Anderson CD, Egilmez NK. Regulatory rebound in IL-12 treated tumors is driven by uncommitted peripheral regulatory $T$ cells. Immunol 2015, 195: 1293-1300. doi:10.4049/jimmunol.1403078 